\title{
POTENCIAL EXPORTADOR: UM ESTUDO DE CASO DA LINHA PRODUTIVA DO ÁGAR-ÁGAR COM ÊNFASE NAS CADEIAS COMPLEMENTARES
}

\author{
A. S. P. CAMILO \& L. F. L. G. COSTA \\ Instituto Federal de Educação, Ciência e Tecnologia do Rio Grande de Norte \\ lucialucio@gmail.com
}

Artigo submetido em novembro/2015 e aceito em dezembro/2015

DOI: 10.15628/empiricabr.2015.3844

\section{RESUMO}

A presente pesquisa possui por objetivo analisar como a cadeia de valor do Ágar-ágar pode gerar competitividade internacional. Para tanto, busca-se realizar um mapeamento da cadeia de valor do processo produtivo do ágar-ágar, das relações de sinergias entre os atores da cadeia produtiva dos hidrocolóides, compreendendo sobre os elementos competitivos de produção no processo de beneficiamento, além de analisar as estratégias de distribuição frente o cenário internacional. Em consonância as teorias, ressaltamse no estudo a cadeia de suprimento e a cadeia de valor, o processo produtivo, acrescenta-se ainda os APL's com benefício às empresas que o compõem e as alianças estratégicas na cadeia de produção abrangendo fornecedores e clientes em seu meio. No desenvolvimento teórico, ainda há o sistema de produção atendendo os objetivos das atividades; e as vantagens competitivas. 0 Paradigma Eclético de Dunning compila as teorias que observam aspectos como localização, competição monopolista, internacionalização e custos de transação para desenvolver o paradigma de Ownnership Localization Internalization e por fim, a Escola de Uppsala com direcionamento ao processo de internacionalização. Para tanto, na pesquisa foi desenvolvida uma investigação estratégica de estudo de caso único sobre a cadeia produtiva, desde a extração, por meio de arranjos produtivos locais, pelo beneficiamento de ágar-ágar e carragena. Por fim, concluiu que a cadeia de valor do ágar-ágar pode gerar competitividade internacional, por meio da associação a cadeias complementares, aplicando-se seu processo produtivo aos canais de adução, canais de drenagem e bacia de decantação presentes no layout estrutural da produção de camarão, tornando possível o crescimento em volume das algas e atendimento a toda demanda.

PALAVRAS-CHAVE: Algas Marinhas, Beneficiamento e Distribuição.

\section{EXPORTING POTENTIAL: A CASE STUDY OF THE AGAR PRODUCTION LINE WITHEMPHASIS ON COMPLEMENTARY CHAINS}

\begin{abstract}
This research has as objective to analyze how the value chain of the agar-agar can generate international competitiveness. To do so, perform a mapping the value chain of the productive process of agar-agar, the synergies between the actors of the productive chain of hydrocolloids, understanding about the competitive elements in the production process, as well as analyze the strategies of the international scenario distribution. Accordingly, theories emphasize the study of supply chain and value chain, the production process, adds the APL's with benefit to the companies that comprise and strategic alliances in the production chain including suppliers and customers in their midst. In the theoretical development, there's still the production system in the light of the objectives of the activities; and the competitive advantages. The Eclectic Paradigm of Dunning compiles the theories that they write
\end{abstract}

things like location, monopolistic competition, internationalization and transaction costs to develop the paradigm of Ownership Localization Internalization and finally, the Uppsala school with direction to the process of internationalization. To this end, the research was developed a strategic research of single-case study on the productive chain, from extraction, through local productive arrangements, for the processing of agar-agar and carrageenan. Finally, it concluded that the value of the agar-agar can generate international competitiveness, by associating the complementary chains, applying its production process to supply channels, channels for drainage and decantation basin present in structural layout of shrimp production, making possible the volume growth of algae and meeting all demand.

KEYWORDS: Marine Algae, Processing and Distribution. 


\section{INTRODUÇÃO}

Dotado de uma extensa área litorânea, o Brasil dispõe de uma ampla gama de riquezas naturais presentes em seu território. Em meio a elas registram-se as algas marinhas, que com a alta frequência do sol e temperaturas constantes da água contribuem para sua proliferação. Esses fatores beneficiam diretamente a região Nordeste como ambiente propicio ao cultivo, ambicionando como especificidade nessa construção o litoral norte-rio-grandense. Nessa região, é possível constatar a forte presença das algas marinhas Rhodophytas, popularmente conhecidos por algas vermelhas, devido a sua coloração. De acordo com Teixeira (2013) essas algas constituem o grupo com o maior número de espécies na costa brasileira, sendo a ordem Ceramiales a mais representativa.

Frente a isso, as motivações do desenvolvimento do projeto, giram em torno das algas vermelhas, com beneficiamento da extração dos hidrocolóides - Ágar ágar e Carragena largamente utilizados na indústria alimentícia e farmacêutica. Em consonância com o autor as algas marinhas são organismos usados como matéria-prima de produtos, como medicamentos, combustíveis, cosméticos, além de servirem como alimento animal e humano. Soma-se ainda a sua função, o desenvolvimento como substância espessante e estabilizantes em sorvetes, doces, derivados de carnes, peixes e leite (como o ágar-ágar e as carragenas, ambos produzidos pelas algas vermelhas). Devido a suas propriedades, possuem alto poder no segmento industrial. 0 autor ainda revela suas funções com direcionamento à culinária oriental, no caso, as algas frescas para consumo humano, como o famoso sushi (bolinho de arroz enrolado na alga vermelha do gênero Porphyra); assim como para fazer copos comestíveis feitos de ágar-ágar, que resolvem os problemas relacionados à produção de lixo, desperdício de água e poluição.

A coleta das algas é realizada de forma manual pelos pescadores, em período de maré baixa, ou também, por mergulho através do uso de equipamentos adequados. Além disso, frequentemente as coletas são efetuadas em recifes de corais próximos à costa. Em busca também de outras experiências de cultivo dentre as linhas produtivas, conjectura-se nesse projeto, no desenvolvimento do cultivo das algas vermelhas, com foco no benefício dos hidrocolóides Ágar-ágar e da Carragena, atrelá-los a carcinicultura, atribuindo benefícios a ambas as frentes de estudo - extração, beneficiamento e distribuição - gerando maior valor e desempenho do produto no comércio internacional. Convém, frente a isso, mencionar que as funcionalidades dos hidrocolóides além de passíveis a aplicação em diversos ambientes, geram por consequência maior demanda, por sua boa aceitação nos mercados internos e externos, exibindo forte poder competitivo, de grande potencialidade.

Dessa forma, buscou-se contribuir com o ambiente interno e externo, observando e compreendo sobre a linha produtiva atual e as possíveis cadeias complementares que contribuam diretamente para um crescente mercado, com potencialidade produtiva para a sua exploração, visando à extração, beneficiamento e distribuição para melhor 
aproveitamento do produto em abundância na região do Nordeste, com grande potencial, mas com baixa atuação no mercado internacional.

Como auxilio no desenvolvimento da presente pesquisa, ambicionou-se em seu objetivo geral - analisar como a cadeia de valor do Ágar-ágar pode gerar competividade internacional. Acrescenta-se ainda, como parte construtiva da pesquisa, os objetivos específicos, direcionamentos à cadeia de suprimento e de valor, processo produtivo, arranjos produtivos locais, alianças estratégicas, sistemas de produção, vantagem competitiva, paradigma eclético de Dunning e Escola de Uppsala. Essas revisões literárias possibilitam um estudo com foco empírico, remetendo a construção da análise de resultados.

A metodologia do projeto apresenta em sua tipologia de pesquisa medidas objetivas, frente ao potencial do beneficiamento dos hidrocolóides. Em seu desenvolvimento ainda apresenta estratégia de pesquisa com fomento em Yin (2001), além de engaja-se a campo diante da coleta de dados, seguida da análise e tratamento dos mesmos, atribuindo ao projeto alinhamento à estratégia. Em contribuição ao ponto relatado, constituiu-se uma metodologia com foco na compreensão sobre a cadeia de valor do ágar-ágar com associação as cadeias complementares, construindo uma pesquisa de estudo descritiva, além de aplicar linha exploratória, com fomento ao retorno da problemática. Relata-se ainda uma abordagem qualitativa, utilizando por coleta de dados o questionário. Mediante construção, além da revisão literária, no desenvolvimento da pesquisa foram relatadas as maiores dificuldades de cada segmento, completando por fim com a contribuição que ambas poderiam se beneficiar em volume e eficiência do ciclo aquático.

\section{REVISÃO BIBLIOGRÁFICA}

O estudo sobre gestão de processo com base na linha produtiva do ágar-ágar com ênfase nas cadeiras complementares revela alguns preceitos teóricos norteadores da pesquisa.

\subsection{Cadeia de Suprimento e cadeia de valor}

A cadeia de suprimento de acordo com Ballou (2006) trata-se de todas as atividades relacionadas com o fluxo e transformação de mercadorias desde o estágio da matéria-prima (extração) até o usuário final, bem como os respectivos fluxos de informação. Materiais e informações fluem tanto para baixo como para cima na cadeia de suprimentos. 0 autor remete a integração dessas atividades como atrelamento ao gerenciamento da cadeia, com o objetivo de conquistar uma vantagem competitiva sustentável.

Segundo o autor, o gerenciamento da cadeia de suprimentos é definido como a coordenação estratégica sistemática das tradicionais funções de negócios e das táticas ao longo dessas funções de negócios no âmbito de uma determinada empresa e ao longo dos negócios no âmbito da cadeia de suprimentos, com o objetivo de aperfeiçoar o desempenho em longo prazo das empresas isoladamente e da cadeia de suprimentos como um todo. Dessa forma, torna importante destacar que o gerenciamento da cadeia de suprimentos trata da 
coordenação do fluxo de produtos ao longo de funções e de empresas para produzir vantagem competitiva e lucratividade para cada uma das companhias na cadeia de suprimentos e para o conjunto dos integrantes dessa mesma cadeia.

\subsection{Processo Produtivo}

O processo produtivo remete a um extenso processo, que parte da matéria-prima até a disponibilidade do produto, seja para distribuição aos fornecedores ou ao cliente final. Tendo em vista o projeto de produção, segundo Chiavenato (1990) sobre os recursos disponíveis, obedecem às seguintes fases: elaboração do plano de produção; Programação de produção (máquinas, materiais e mão-de-obra); Emissão de ordens de produção e Liberação da produção.

O autor trata o plano de produção estando sujeito a fatores determinantes, nos quais podem constituir vantagens que a empresa pode aproveitar ou restringir a partir das limitações que impedem de produzir mais. Os principais fatores determinantes do plano de produção são as previsões de vendas que constitui a expectativa de vendas da empresa; capacidade de produção que representa o potencial produtivo da empresa; disponibilidade de matérias-primas no mercado fornecedor; e recursos financeiros que a empresa tem a sua disposição para adquirir matérias-primas e demais recursos para produzir.

\subsection{Arranjo Produtivo Local}

Os arranjos produtivos locais possuem como contribuinte pioneiro - Marshall (1982) por retratar os benefícios que obtêm as empresas por se localizarem em um determinado espaço. Ou seja, o autor traz uma visão de possibilidade de divisão de trabalho com a união de empresas em um determinado espaço geográfico, gerando por consequências benefícios frente à economia externa.

Para Souza Junior, Cario e Fernandes (2011) a ação conjunta intencional e ou incidental na atividade econômica exercida, gera maior desenvolvimento aos envolvidos. Destacando ainda a ação conjunta conscientemente exercida, podendo esta ser a partir da cooperação de empresas - compartilhamento de equipamentos ou desenvolvimento de novos produtos - ou ainda grupos de empresas, congregando forças em associações empresariais e em consórcio de produtores, entre outros. 0 autor ainda remete os ganhos decorrentes à noção de eficiência coletiva. Entretanto, não exclui a existência de conflito ou competição entre as empresas do cluster.

\subsection{Alianças estratégicas na cadeia de produção}

As alianças estratégicas concernem a uma variedade de diferentes arranjos cooperativos, normalmente entre fornecedores e clientes, com cada vez mais frequência, concorrentes em outros domínios (MINTZBERG; AHLSTRAND; LAMPEL, 2000). Entretanto, como discutido pelos autores a cooperação tem limite, as empresas precisam preservar a noção de defesa contra concorrentes. 
Relatam ainda, que uma aliança estratégica é uma barganha em constante evolução, cujos termos reais vão além do contrato legal ou das intenções da alta gerência. A troca de informações é determinada no dia-a-dia, com frequências por engenheiros e gerentes operacionais. As empresas bem-sucedidas mantêm os funcionários de todos os níveis informados a respeito de quais competências e tecnologias estão vedadas aos parceiros e monitoram aquilo que estes solicitam e recebem.

\subsection{Sistemas de produção}

De acordo com Neumann (2013) todos os sistemas que produzem algo lhes adicionando valor e atendendo aos objetivos predefinidos pela organização são denominados de sistemas produtivos. Dentre esses existem os que produzem bens físicos, os que prestam serviços ou ambas as coisas. 0 autor ainda relata que os sistemas produtivos (sistemas de produção/sistemas de operações) são compostos por processos produtivos (processos de produção de processos de fabricação). Ainda em consonância com o autor, o objetivo dos sistemas produtivos consiste em maximizar a cadeia produtiva e transferir, para o cliente final, os ganhos advindos do relacionamento eficiente entre clientes e fornecedores.

De acordo com Neumann (2013) os sistemas de produção são uma coleção ou um arranjo de processos de fabricação e de produção encadeados utilizados para fabricar bens físicos, em uma sucessão de estados. Retrata ainda, que concerne a uma entidade que organiza um conjunto de recursos tecnológicos, econômicos, humanos, físicos e financeiros em materiais, equipamentos, instalações, processos e procedimentos com o objetivo da produção de um bem físico.

\subsection{Vantagens competitiva Internacional}

A vantagem competitiva segundo Porter (1989) prospera fundamentalmente da melhoria, inovação e mudança. As empresas obtêm vantagem sobre rivais internacionais porque percebem uma nova base para a competição ou descobrem novos e melhores meios de competir da velha maneira.

0 autor relata que a inovação, em termos estratégicos, é definida no mais amplo sentido. Inclui não só novas tecnologias, mas, também, novos métodos ou maneiras de fazer as coisas que, por vezes, parecem lugares-comuns. A inovação pode manifestar no projeto de novos produtos, em novo processo de produção, nova abordagem, qualquer atividade de cadeia de valores.

Nos mercados internacionais, as inovações que proporcionam vantagem competitiva preveem as necessidades não só internas como, também, externas. 0 autor ainda traz a visão de que algumas inovações criam vantagem competitiva quando a empresa percebe a necessidade de um comprador totalmente novo ou serve ao segmento do mercado que os rivais ignoram. Surge uma vantagem porque os competidores estrangeiros, com frequência, demoram a reagir de maneira eficiente. As inovações que levam à vantagem competitiva também se baseiam, com frequência, em novos métodos ou nova tecnologia que tornam 
obsoletos bens e instalações existentes. Os rivais não reagem devido ao medo de apressar a obsolescência de seus investimentos passados.

\subsection{Paradigma Eclético de Dunning}

O paradigma eclético busca explicar os padrões de internacionalização através de três variáveis:

Ownership (vantagem de propriedade): essa variável se destina a análise da organização em posicionamento estratégico (PORTER, 1989) superior às concorrentes no mercado exterior. São considerados principalmente ativos intangíveis na determinação dessa vantagem, tais como: tecnologia; recursos humanos; informações; marcas; patentes; processos produtivos, dentre outros; localization (vantagem da localização): essa vantagem está relacionada com a vantagem que pode ser desenvolvida pela empresa se considerados aspectos determinados de cada país ou região onde a empresa está localizada. São geralmente considerados aspectos como custos de mão-de-obra, impostos domésticos, infraestrutura, entre outros. internalization (internalização): essa vantagem considera a capacidade da organização internalizar vantagens de propriedades adquiridos em mercados externos. Assim, o autor sugere que quando os custos de transação forem superiores aos de incorporação, a organização tende a internalizar-se no mercado passando a atuar como fabricante.

\subsection{Escola de Uppsala}

Johanson e Vahlne (1977) propõem um modelo baseado em observações empíricas realizadas em estudos na Universidade de Uppsala, baseados no paradigma comportamental, que mostram que as empresas suecas geralmente desenvolvem as operações internacionais em pequenos passos ao invés de realizarem grandes investimentos em momentos esporádicos. Geralmente, as empresas começam a exportar para outros países via agentes, posteriormente estabelecem subsidiária de vendas e eventualmente, em alguns casos, iniciam a produção no país hospedeiro (KOVACS, MORAES e OLIVEIRA, 2007).

O modelo proposto pelos autores conhecido como o modelo de Uppsala (U-Model) evidencia também a perspectiva sequencial de processo de internacionalização. A investigação tomou por base quatro empresas, cuja característica comum é o padrão linear do desenvolvimento das suas operações internacionais. 0 modelo é baseado no desenvolvimento do conhecimento e comprometimento crescente no país estrangeiro.

\section{METODOLOGIA}

Ponderando esse projeto a partir do objetivo principal, em buscar compreender sobre como a cadeia de valor do Ágar-ágar pode gerar competividade internacional por cadeias complementares, com o intuito de incrementar o produto de maneira a posicionar-se fortemente no mercado internacional, o enquadramento desse estudo pode-se considerar de caráter descritivo, por permitir a observância de processos complementares, passível de 
contribuição no desempenho internacional. Ainda se pode verificar na pesquisa, uma linha exploratória, por submeter uma problemática que guiará as hipóteses com maior precisão, gerando atenção e detalhamento em potenciais dificuldades. Constata-se ainda em seus conjuntos respectivos, em conformidade com Gil (2010) que é possível determinar as hipóteses subjacentes, mediante a análise dos instrumentos adotados para a coleta de dados.

Considerando na construção da pesquisa a estratégia de estudo de caso único, enquadra-se como uma abordagem qualitativa, normalmente utilizada para coleta de dados. De acordo com Yin (2001) a escolha pela adoção do método por meio de estudo de caso é adequada quando são propostas questões de pesquisa do tipo "como" e "por que", e nas quais o pesquisador tenha baixo controle de uma situação que, por sua natureza, esteja inserida em contextos sociais. A priori, os dados da pesquisa foram obtidos via entrevista semiestruturada com vislumbro aos arranjos produtivos locais, obtendo a partir desse meio, esclarecimentos quanto a extração, o beneficiamento das algas e a distribuição, ambicionando compreender o desenvolvimento atual e o que se pode contribuir para um aprimoramento no desempenho do produto em âmbito internacional. Com base no referencial desse projeto, tornou-se possível a elaboração de perguntas direcionadas ao questionamento necessário para entendimento e construção da pesquisa.

Essa construção é apresentada a partir da interpretação do que foi realizado na coleta de dados com a AgarGel e a Associação Brasileira de Criadores de Camarão (ABCC), utilizando como fator essencial o instrumento de coleta utilizado, que nessa pesquisa constituiu-se pelo questionário, desenvolvido e confrontado ao Referencial Teórico. A partir dos resultados brutos, privilegiando a análise qualitativa, atribuindo força a argumentação, gerando aproximação ao tema estudado.

\section{ANÁLISE DE RESULTADOS}

Com base na gestão de processo, busca-se compreender a relação do beneficiamento dos hidrocolóides com fomento da cadeia complementar da carcinicultura. Abaixo apresentam-se alguns dados sobre o assunto, proveniente de profissionais das áreas competentes.

\subsection{Produção de Algas Marinhas com beneficiamento de Hidrocolóides}

Localizada com seus pontos de vendas em São Paulo e Fábrica instalada no Distrito industrial do estado da Paraíba, em João Pessoa, a empresa AgarGel dedica-se à produção de ágar-ágar e carragena, hidrocolóides extraídos de algas marinhas vermelhas utilizados como gelificante, espessante e estabilizante em diversas aplicações industriais. Sua localização favorece o desenvolvimento da produção, compilando a construção do paradigma eclético de Dunning no posicionamento estratégico - Ownership - além de fundamentar as vantagens de localização - Localization - devido à escolha voltada para a região nordeste, na qual o clima, território e acesso favorecem a empresa e busca pela matéria-prima utilizada na produção. Diante disso, estabelecem uma forte base com efeito na infraestrutura, localização e acesso as 
matérias-primas de forma privilegiada, beneficiando no processo de internacionalização, composta pelos autores Johanson e Vahlne (1977), onde remetem ao desenvolvimento de internacionalização das empresas.

0 processo de produção baseia-se no método Gel Press, no qual consiste das seguintes etapas: Classificação de matérias-primas, tratamento químico, lavagem, extração a quente; filtração da solução, gelificação, prensagem do gel; secagem; moagem; padronização e embalagem, atendendo atividades relacionadas com o fluxo e transformação da mercadoria, em consonância com Ballou (2006). Além disso, ressalta que a empresa conta com um rigoroso controle de qualidade aplicada a todas as etapas do processo de produção, desde a aquisição de matérias-primas até a obtenção do produto final, visando atender às mais exigentes especificações técnicas, em conformidade com o processo produtivo, presente na construção literária, apresentada por Chiavenato (1990).

Segundo o sócio administrador da empresa, o processo inicia a partir da coleta das algas, por meio dos pescadores, via por onde se adquire a matéria. Na atualidade adquirem-se algas coletas do Norte do Ceará, devido à Paraíba e do Rio Grande do Norte possuir o custo alto comparado com o dólar, que fez também com que passassem a importar matéria-prima da Indonésia e Filipinas, processando o produto em ambiente interno. Em consonância com as alianças estratégicas relatadas por Mintzberg, Ahlstrand e Lampel (2000), no seu suprimento com fornecedores e compromisso com clientes.

Ainda de acordo com o sócio, na atualidade a empresa importa o produto já pronto, por não estarem realizando o beneficiamento, as importando beneficiada e padronizando com a qualidade da empresa. Assim, concluem a linha de produção passando a mercadoria para os seus clientes externos e internos. Dentre os clientes que compõem a cadeia de demanda da empresa, tem-se em mercado externo com o Japão e em mercado interno com o MERCOSUL Argentina, Brasil, Uruguai, Paraguai e Venezuela, além dos associados Chile e Bolívia. Atendendo cerca de $40 \%$ do mercado externo, mantendo o restante (cerca de 60\%) em ambiente interno. Como proposto no modelo de Uppsala, com direcionamento ao processo de internacionalização, vislumbrando o desenvolvimento do conhecimento e comprometimento crescente no país estrangeiro.

Em concernência a aplicação do produto, de acordo com o administrador, o forte ponto de utilização instala-se na indústria alimentícia, a maioria usada para a produção de doces, como geleia de mocotó, sorvetes, pudins e flãs. Dentre suas utilizações o administrador acrescenta que em meio à produção e distribuição, parte é remetida ao combate contra as vespas da cana, na qual se alimenta com o ágar. Assim, parte dessa produção é direcionada para mercados como Arisco e Kibon. Como relatado pelo sócio da AgarGel;

A ideia inicial da empresa era comprar as algas e exportar para o Japão. Porém, para retirar a licença do governo para coleta, tivemos que remeter metade do que coletasse a industrialização para beneficiamento, angariando os custos, a partir desse ponto começa a industrializar. Inicialmente buscou-se in natura e exportavam processo iniciado com um diretor de Taiwan que pegava em Santos, litoral paulista, levava para casa, tratava e exportava. Após três anos começaram a industrializar. 
Na parte industrial revela ser uma particularidade da empresa. Devido à concorrência que importava e revendia, passando a vender até a preço de custo da AgarGel, a empresa teve que se adequar aos nossos mercados, iniciando o processo de importação, para não perder seus clientes para mercados de baixo custo. Entretanto, a empresa confirma como diferencial frente aos demais, a processo de beneficiamento, já que é a única que realiza o processo. Contemplando fundamentalmente em melhoria, inovação e mudança relatada por Porter (1989), frente às vantagens competitivas.

O escoamento do processo de produção em sua normalidade ocorre por Suape e/ou Pecém, optando por modais de transportes como o aéreo e o marítimo. A escolha do modal aéreo ocorre com direcionamento ao mercado Japonês, que mesmo sendo uma mercadoria com frete quantificado a partir do peso, o cliente opta por essa via devido à rapidez e segurança do processo, optando por arcar até com os custos elevados do modal escolhido. Em meio à emissão de pedidos, o sócio relatou que nesse ambiente de processamento de pedidos, a empresa já possui uma cadeia de clientes, nos quais se solicita um mesmo quantitativo, gerando uma relação de controle e, por conseguinte, suprindo da demanda - adicionando valor e atendendo os objetivos da organização de ser eficiente frente ao atendimento da demanda e da linha logística, entrando diretamente em concordância com o autor Neumann (2013).

No procedimento de aproveitamento das algas marinhas, o rendimento da matériaprima depois de seca corresponde em torno de 15\%, dessa forma, 85\% representa desperdício. 0 administrador explica ainda que transformando para quilo, essa representatividade desenvolve a cada $100 \mathrm{~kg}$ de alga marinha seca, retira-se $15 \mathrm{~kg}$ de alga. Acrescentando ainda, a importância que tem das algas marinhas estar com $20 \%$ a 25\% do peso, já que em processo de extração as algas perdem em torno de $75 \%$ do seu peso. Esse envolvimento gera a empresa entre custos diretos e indiretos um percentual de $60 \%$. A partir disso, com o desenvolvimento em mercado interno e externo, acaba-se fornecendo um retorno de 5\% ao ano a AgarGel.

0 produto depende diretamente da qualidade da matéria que é importada, garantindo que a empresa atenda seu mercado, no qual corresponde a $15 \%$ a $20 \%$. 0 restante (80\%) se relaciona a importação direta, sendo o Brasil um país que importa muito do produto, já que consome em demasia. A essência é estabelecida no comprometimento em suprir a demanda desses 20\% (aproximadamente), atendendo a diversos clientes que atribuem fidelidade a empresa.

Grandes clientes no mercado, como Arisco e Sadia, desejavam comprar toda a produção da empresa. Entretanto, essa ação traria uma dependência da empresa frente ao cliente, optando por atender parte da demanda de grandes clientes e pequenos mercados. Assim, vendem cerca de $300 \mathrm{~kg}$ para pequenos clientes, que acaba gerando um maior retorno de lucros. Logo, enfatiza não haver problema na venda, devido à alta demanda, mas na produtividade, como ressalta o sócio administrador.

No ano de 2007, a empresa decidiu iniciar o processo de importação, para esse procedimento a AgarGel necessitaria, a priori, de capital de giro, justificado pelo processo, 
onde a empresa solicita a mercadoria, segue ao processo de pagamento e recebem apenas após dois meses. Incialmente ainda compravam um pouco do litoral, hoje procedendo apenas através da importação, não produzindo no momento atual. Segundo o administrador;

No processo, ainda coletavam de Itapuí - divisa do Rio Grande do Norte e Paraíba minimizando o peso de coleta, informando os pescadores da parada de compra, para não perderem produto. Nesse período retiravam cerca de 70 toneladas de algas secas de Itapuí. Coletaram também de ambientes litorâneos como Muriú e Maracajaú. Além de cabedelos.

Segundo o sócio administrador da empresa AgarGel as algas concernem a um produto não perecível, podendo armazena-la seca, refrigerada, por aproximadamente um ano e meio. Frente a isso, torna-se possível controlar a produção e o suprimento das demandas em acordo com o estoque de mercadoria.

0 administrador acrescenta em discurso, o equilíbrio do Chile frente ao mercado, devido a cultivo que estabelecem. Refletindo ainda sobre a ausência de algas nos bancos e costas do Nordeste, mesmo que não ocorra um desequilíbrio de retirada. Devido a essa falta, a empresa começou a importar e preveniu-se contra possíveis ineficiências. Na época em que parou de coletar em meio interno (2007), as algas internas já eram insuficientes para a demanda. Importar das Filipinas foi o primeiro procedimento de adequação do mercado, confirmando a literatura do autor Neumann (2013).

Em relato, revelou-se ainda como forma de pagamento utilizada pela empresa à carta de crédito, também conhecida por crédito documentário, sendo a modalidade de pagamento mais difundida no comércio internacional, por oferecer maiores garantias, tanto para o exportador como para o importador. Acrescenta-se ainda, as formas como gerenciam os custos, remetendo a situações de pesquisas, para que tudo se alinhe, de forma a minimizar custos para a AgarGel. Entretanto, conforme relatado, a maior problemática para a empresa em tempos atuais, é a matéria-prima, assim como, a mão-de obra.

Acrescenta-se ao seu discurso os períodos de piores resultados de coleta - julho, agosto e setembro - que é contribuído ainda, pelo fato de não ter os pescadores organizados como uma associação, o que contribuiria para um menor impacto nesses períodos citados.

Em conformidade com os custos associados, soma-se o preço da tonelada, sendo em torno de US $\$ 100,00$, já para importar já beneficiada, o preço estabelece em torno de US\$300,00. Em ambiente interno, o preço da tonelada é determinado no mesmo parâmetro de US\$100,00. Esse procedimento ocorre de acordo com a meta estabelecida em torno do rendimento, que deverá atingir $15 \%$ para que ocorra o escoamento da mercadoria no mercado.

0 processo produtivo, quando ocorrido internamente, gera procedimentos como o recebimento das algas, sendo postas ao processo de retirada da areia, seguida ao ponto da lavagem das algas, partindo para o momento de secagem. Em conformidade com o administrador; 
Na empresa - AgarGel - trabalha-se com três tipos de algas, são elas utilizadas no Japão, nas quais fazem o tratamento e usam em salada para comer com o peixe cru, típico da região. As demais, utilizadas para extrair o ágar-ágar, com funções gelificantes, de onde é gerada a farinha. E em menor proporção a carragena, com função de conservante (utilizada para embutido-frigoríficos).

A demanda do gelificante fica em torno ou quase igual à demanda do conservante. Em conformidade com o sócio administrador se a sua produção fosse direcionada a clientes como Arisco e Perdigão, não teria como suprir a demanda, além de gerar dependência a empresa. Logo, a AgarGel opta por vender para os menores, já que assim conseguem atender a demanda, satisfazer a necessidade de seus clientes, sem gerar o ônus da dependência da empresa frente a poucos clientes.

Dentre os equipamentos que compõem a linha produtiva, além de maquinários de produção própria, há equipamentos alemães, da marca Next. 0 sócio ainda enfatiza a importância de manter uma regularidade na manutenção de seu maquinário, para que não gere um custo desnecessário e imprevisível para o ambiente interno.

Em conformidade com o sócio da AgarGel, os grandes acabam importando de forma direta, para que ocorra um suprimento eficiente do seu processo produtivo interno. A AgarGel sozinha não tem como suprir essa logística, já que ocorre ausência do produto bruto, devido a demora do processo logístico. A importação é feita através do modal hidroviário, demorando dois meses até que a mercadoria chegue à empresa, tendo por função da empresa, pagar um mês antes pelo pedido e, quando a mercadoria chega ao ambiente interno da empresa, ainda ocorre a preparação. Esse procedimento gira em tempo, de seis a sete meses para a organização, com um planejamento estratégico que consiga suprir a demanda dos seus clientes.

Em meio aos contratempos, ainda contam com um processo de liberação, estabelecida em ambiente portuário. Após os dois meses de transporte hidroviário. Escoando para seus vários clientes, vendendo em torno de $600 \mathrm{~kg}$. Historicamente, no início de seus trabalhos, em concernência as parametrizações caiam no canal vermelho, onde além de conferência documental, é feita a conferência física da mercadoria. Em consonância com o administrador;

Mesmo diante da situação de planejamento, nunca tivemos problemas com prazos, direcionados aos clientes, por orientarmos que façam o pedido com antecedência. Além disso, ressaltamos o período em que a mercadoria deverá chegar, para evitar maiores situações de desconfortos com os clientes. Essa falta de mercadoria e processo logístico realizado ocorre pela falta de mercadoria na empresa, já que não há em condições atuais de manter um estoque.

O quantitativo para quem coleta algas precisa ser de grandes proporções, já que quando seca, perde grande parte de seu peso. Para que não necessitassem importar, a empresa precisaria de uma quantia mensal, da alga seca, de 100 a 150 toneladas. No mercado interno, esse suprimento não é possível, sendo ineficiente. Esse fator fez com que a empresa optasse pela busca do produto no mercado externo, importando a quantidade de suprimento, atribuindo eficiência. 0 entrevistado traz ainda a associação do cultivo com cadeias complementares, com direcionamento ao camarão. Relatando a existência de pesquisas, 
comprovando sua rentabilidade, de forma a aperfeiçoar, tornando o rendimento quantitativo de elevadas proporções, que os atribuam volume, exclusivamente do produto já seco. No RN, especificamente em Pitimbu, ocorre um processo de coleta manual. Entretanto o custo fica muito alto para cultiva em grandes proporções. A empresa ainda produziu 10 toneladas no ambiente, e segundo o administrador o resultado saiu, mas tem que estar todos envolvidos, levando o procedimento como negócio.

\subsection{Abordagem Estratégica Complementar}

A escolha da ABCC para integrar o presente estudo deu-se a partir do interesse em compreender um pouco mais sobre o setor de carcinicultura, além de principalmente buscar relatos de autoria com direcionamento a associação entre macroalgas e o cultivo de camarão. A partir disso, o presente texto discutirá sobre os aspectos internos e externos com encaminhamento ao estudo das algas marinhas vermelhas.

A ABCC tem por objetivo promover o desenvolvimento da carcinicultura em todo o território nacional, o que envolve a defesa dos interesses setoriais e de seus associados, promoção de estudos e pesquisas em áreas direta ou indiretamente relacionadas com a atividade; organização e patrocínio de encontros empresariais, simpósios e conferências sobre aspectos técnico-científicos, comercial e demais temas relacionados com o desenvolvimento da carcinicultura. Realização de estudos setoriais, envolvendo os diversos temas relacionados com o desenvolvimento sustentável da carcinicultura brasileira e com os temas relacionados à nutrição, genética, doenças, sanidade, maturação, larvicultura e engorda, bem como, edição de publicações especializadas; relacionamento formal com entidades congêneres, nacionais ou estrangeiras. Celebração de protocolos e convênios com órgãos governamentais; promoção de reuniões com entidades representativas de classes econômicas, pessoas físicas e jurídicas, credenciamento de fornecedores de insumos e equipamentos e de firmas de consultoria técnica, incluindo certificadoras e detentoras de selos de qualidade para a carcinicultura; enfim, a realização de Feiras de Aquicultura, incluindo adicionalmente toda e qualquer atividade que interaja direta ou indiretamente com a carcinicultura e o interesse de seus associados. Confirmando os benefícios dos arranjos produtivos locais como registrados por Marshall (1982).

Como principal benefício atribuído aos associados, remete a proteção, em uma escala macro, lutam pelo setor como um todo. Sendo na pratica 2000 produtores afiliados. Entretanto foi instituído em assembleia da ABCC, que todos os produtores de camarão ao comprarem ração, de forma automática tornam-se associados. Segundo o engenheiro de pesca;

Dessa forma, a associação se mantem por meio de algumas mensalidades advindas de laboratórios, bem como, fornecedores. Entretanto, esse fator remete a uma exceção, já que a grande parte da receita da ABCC vem da CPE - Contribuição Permanente de Ração, antigamente conhecida por Fundo de Ração. Isso remete a cada tonelada adquirida pelo produtor $\mathrm{R} \$ 20,00$ destina-se a ABCC, juntamente com a filiada estadual. 0 ônus estabelece por determinar um acordo de confiança, a arrecadação dáse via declaração, correndo os riscos como sonegação. 
O cultivo do camarão marinho, com a tecnologia existente os possibilitam em uma produção de camarão até em água doce. A tecnologia hoje se faz aliada ao crescimento. Algumas fazendas tem uma estrutura mais adequada. As larvas chegam com uma realidade e passa por um processo de adequação para que se acostume à nova realidade, minimizando riscos, perdas, e maximizando em uma produção mais rápida e agiu.

O engenheiro de pesca ressalta a Síndrome da mancha branca, que chegou enfraquecendo a produção nacional. Seguida da adequação realizada na maneira de produzir camarão com essa nova realidade. Certos cuidados foram atribuídos ao procedimento. De forma que na atualidade o animal passa pelo processo de pré-engorda, a priori, a crescimento é freado, só depois acontece o crescimento compensatório. Ou seja, tudo o que não cresceu no momento inicial, cresce no procedimento de crescimento compensatório. Esse processo dá-se por meio da nova realidade, da adequação que se tornou necessária.

Soma-se a isso, a existência de uma parte do procedimento em ambiente laboratorial, já que as larvas não são capturadas em ambiente natural, trabalhando com uma espécie natural do pacifico.

0 processo de produção, a priori, passa pelo acompanhamento laboratorial de maturação, seguida da coleta de ovos. A partir desse procedimento, torna-se possível a continuação do ciclo, com ida a larvicultura, nesse ambiente a larva está em um processo de pós-larva 1, 2, 3. Pós 10 e 15 dias de vida, ainda estão na parte laboratorial.

Os custos minimizados, gastando menos tempo de forma mais eficiente, com a atribuição de um rápido fluxo de caixa. Optam por ciclos mais curtos, para os empresários e produtores, é uma forma aprimorada. Mais interessante produzir três vezes um de oito gramas, do que produzir uma vez, sendo ele de vinte quatro gramas, além de um risco maior, já que a perda de um animal acarretaria em uma perda muito grande. Já que todo o investimento que foi realizado no processo seria perdido.

No sistema arcaico, ou seja, tradicional contam com um sistema mais demorado, menos especifico, com maiores riscos. Por isso, a adaptação a atual situação faz-se necessário ao seu retorno de investimento. Essas técnicas foram realizadas através de viagens para a Ásia, nas quais possibilitaram maior conhecimento sobre o assunto, buscando aprimorar-se em suas pesquisas, o que acarretou no somatório satisfatório de informações, formando um pacote adaptado ao ambiente interno, ressalta o engenheiro.

Cada ida ao meio externo obtinha informações que contribuíam no processo de adaptação e crescimento da produção em ambiente interno. Acrescenta-se ainda que o pacote tecnológico existe, a maior dificuldade é o governo.

Segundo o entrevistado nos sistemas de fase de produção do camarão, engloba-se a fase de laboratório, seguida pela de larvicultura de maturação e a de larvicultura. Ressaltando o atendido da associação em esfera federal. Dependendo da demanda ajudamos, ou como em muitos outros momentos, somos ajudados, com novos procedimentos e pesquisas.

Em relação à Lei Pereira Cortez, o engenheiro de pesca atribui positiva relação, já que regularizou a implementação da atividade da carcinicultura na nomenclatura agrosilvipastoris, ou seja, o Instituto de Desenvolvimento Sustentável e Meio Ambiente IDEMA - deve liberar a licença ambiental. Liberando o licenciamento ambiental, os criadores 
têm acesso ao financiamento. Diante disso, obtendo acesso ao crédito, os produtores podem crescer, fazendo crescer também a economia, e prosperarem. Logo, a Lei só veio a trazer positivas relações ao segmento, como relata o entrevistado.

Dentro do ambiente de associação, de acordo com o engenheiro de pesca, não existe vantagem competitiva, a associação não traz essa função. Logo, os produtores não competem entre si, se ajudam. Já que o que se produz não dá para quem quer, com uma demanda reprimida, não conseguem atendem a todos os públicos.

Na situação de exportação em 2006, quando buscavam atingir mercados externos, existia concorrência, entretanto, nas condições relatadas não haveria razão em se ter uma vantagem competitiva. Frente a isso, não há competição, entretanto, há incentivo ao incremente produtivo.

\subsubsection{Associação Produtiva}

No contexto de linha produtiva do ágar-ágar com ênfase na cadeia complementar carcinicultura - o engenheiro traz essa relação pouco interessante quando se fala do viveiro, devido ao consumo de oxigênio que a alga geraria, afetando diretamente o crescimento de seus camarões, geram biomassa, sugam os nutrientes. Então, tudo o que for fertilizado, será absorvido pelas algas, afetando diretamente no crescimento dos camarões. Logo, nem as algas irão crescer como desejam, nem os camarões.

Entretanto, ressalta extrema importância do cultivo de algas, com fomento ao beneficiamento dos hidrocolóides Ágar-ágar e Carragena, nos canais de adução, canais de drenagem e bacia de decantação, dependendo do layout da fazenda, devido a sua função filtradora, beneficiando diretamente dois setores.

Nos canais de adução e de drenagem faz-se interessante, já que existe um layout de uma fazenda de camarão, no qual o canal de adução é o que vai alimentar com água os viveiros. E na necessidade de completar a água que evapora e/ou que infiltra, faz-se necessário tirar água que está dentro, para pôr uma nova. Para tanto existem os canais de drenagem. A bacia de sedimentação, sendo exigência dos órgãos ambientais, realiza o escoamento da água para o canal de adução, nesse ambiente acabam vindo peixes, camarões, algas, caranguejo, siri, virando um ecossistema à parte.

Em conformidade com o entrevistado seriam interessantes nesse ambiente as algas, porque a mesma filtraria a água que vem dos viveiros, ainda com nutrientes. As algas irão absorver esses nutrientes em excesso, e assim, quando a água é devolvida para o rio, retorna com excelente qualidade, apta ao uso. Quão melhor puder voltar à água, diante de sua qualidade, ou reutiliza-la, melhor. Melhor para o ambiente, cumprindo também determinações ambientais, e sendo extremamente importante para o produtor, a exigência da recirculação, para os produtos é de elevado beneficiamento.

\section{CONSIDERAÇÕES FINAIS}

Esta pesquisa se propôs em sua construção analisar como a cadeia de valor do ágarágar poderia gerar competividade no contexto internacional. Para tanto, desenvolveu um 
estudo baseado na empresa AgarGel com direcionamento ao beneficiamento de ágar-ágar e carragena - hidrocolóides extraídos de algas marinhas vermelhas utilizadas como gelificante, espessante e estabilizante em diversas aplicações industriais - além disso, baseou-se também na Associação Brasileira de Criadores de Camarão (ABCC), na qual atribuiu os benefícios da associação do cultivo de camarão unido a produção de algas. Para tanto a captação dos dados tornou-se possível a partir da construção dos princípios literários - Cadeia de suprimento e cadeia de valor, processo produtivo, arranjos produtivos locais, alianças estratégicas, sistemas de produção, vantagem competitiva, paradigma eclético de Dunning e Escola de Uppsala.

Mediante construção, na empresa pesquisada - AgarGel - se analisa um processo produtivo baseado no método Gel Press, que vem a atender as atividades relacionadas com o fluxo e transformação da mercadoria, em consonância com Ballou (2006). No tópico literário que remete ao processo produtivo, tornou-se possível analisar, em conformidade com Chiavenato (1990) o rigoroso controle de qualidade aplicada a todas as etapas do processo de produção, desde a aquisição de matérias-primas até a obtenção do produto final.

Os arranjos produtivos foram contemplados na ABCC, na qual possui por objetivo promover o desenvolvimento da carcinicultura, em todo território nacional, com fomento na defesa dos interesses setoriais e de seus associados, confirmando os benefícios dos arranjos produtivos registrados por Marshall (1982). Nas alianças estratégicas, em consonância com as Mintzberg, Ahlstrand e Lampel (2000), revelaram-se na empresa uma variedade de diferentes arranjos cooperativos que a empresa une, entre seu suprimento com fornecedores e compromisso com clientes.

No que concerne ao sistema de produção, a empresa revela em meio à emissão de pedidos, uma cadeia de clientes, nos quais solicitam um mesmo quantitativo, gerando uma relação de controle e, por conseguinte, suprindo da demanda - adicionando valor e atendendo os objetivos da organização de ser eficiente frente ao atendimento da demanda e da linha logística, entrando diretamente em concordância com o autor Neumann (2013). Ainda no acervo literário, com direcionamento as vantagens competitivas, a empresa adequou as mudanças do mercado, iniciando o processo de importação, para não perder seus clientes para mercados de baixo custo. Entretanto, a empresa confirma como diferencial frente aos demais, a processo de beneficiamento, já que é a única que realiza o processo, contemplando Porter (1989).

Em referência ao paradigma eclético de Dunning, há uma relação por meio da escolha da localização, com direcionamento ao favorecimento e desenvolvimento da produção, posicionando estrategicamente não só diante da produção, mas devido ao escoamento. Devido à escolha voltada para a região Nordeste, na qual o clima, território e acesso favorecem a empresa e busca pela matéria-prima utilizada na produção. Diante disso, estabelecem uma forte base com efeito na infraestrutura, localização e acesso as matérias-primas de forma privilegiada, beneficiando no processo de internacionalização. Em meio a isso, o paradigma de Dunning possui relação direta a pesquisa, devido à localização privilegiada da produção da empresa e da cadeia complementar. Ambos se beneficiariam, com um ambiente de temperaturas constantes, clima favorável às duas linhas produtivas. 
No processo de associação a revisão literária, o tópico referente à Escola de Uppsala, é relatado mediante exportações da empresa, que contribui diretamente na expansão da produção, com direcionamento ao Japão, movido ao envolvimento de internacionalização, trazido pelos autores Johanson e Vahlne (1977). Além disso, envolvem-se no processo de internacionalização com o processo importação no suprimento de demanda, com visão voltada ao aumento de volume de algas secas para atendimento de mais clientes, aumentando o grau de internacionalização.

Desse modo, diante do desenvolvimento literário, na extração dos dados, seguida da análise dos mesmos tornou-se possível compreender de acordo com o sócio administrador da AgarGel que a associação do cultivo com cadeias complementares, com direcionamento ao camarão é viável e rentável, além de proporcionar a ambos os segmentos uma excelente utilização, de forma a ambos se beneficiarem. Ressalta o aperfeiçoamento para que o rendimento seja quantitativamente de elevadas proporções, que os atribuam volume, exclusivamente do produto já seco. Para o setor, atendendo a esse requisito de volume e qualidade, seria de grande valia.

No contexto apresentado pelo engenheiro de pesca da ABCC, no contexto de linha produtiva do ágar-ágar com ênfase na cadeia complementar - carcinicultura - o engenheiro traz essa relação pouco interessante quando se fala do viveiro, devido ao consumo de oxigênio que a alga geraria, afetando diretamente o crescimento de seus camarões, geram biomassa, sugam os nutrientes. Entretanto, ressalta extrema importância do cultivo de algas, com fomento ao beneficiamento dos hidrocolóides Ágar-ágar e Carragena, nos canais de adução, canais de drenagem e bacia de decantação, dependendo do layout da fazenda, devido a sua função filtradora, beneficiando diretamente dois setores.

Nos canais de adução e de drenagem faz-se interessante, já que existe no layout de uma fazenda de camarão, no qual o canal de adução é o que vai alimentar com água os viveiros. E na necessidade de completar a água que evapora e/ou que infiltra, faz-se necessário tirar água que está dentro, para pôr uma nova. Para tanto existem os canais de drenagem. A bacia de sedimentação, sendo exigência dos órgãos ambientais, realiza o escoamento da água para o canal de adução, nesse ambiente acabam vindo peixes, camarões, algas, caranguejo, siri, virando um ecossistema à parte, conforme o engenheiro de pesca.

A partir desse entendimento, conclui-se que a cadeia de valor do ágar-ágar pode gerar competitividade internacional, por meio da associação as cadeias complementares, no caso do estudo - a carcinicultura. Esse entendimento foi construído por meio dos dados primários, coletados com aplicação a AgarGel e a ABCC, na qual se tornou possível compreender até onde a associação entre duas produções seriam possíveis. A partir disso, como beneficio as duas produções constataram-se os locais possíveis de aplicação - canais de adução, canais de drenagem e bacia de decantação - na qual as algas terão como função filtrar os sedimentos, atribuindo maior volume ao setor mercadológico, com encaminhamento no atendimento dos clientes, tornando assim mais eficiente. A pesquisa limita-se aos canais de adução e drenagem e a bacia de sedimentação, a partir do esclarecimento do engenheiro de pesca da ABCC, que traz uma visão negativa do cultivo das algas dentro dos viveiros, devido à quantidade de 
oxigênio que as algas absorveriam, tornando os dois cultivos pouco eficientes. A partir disso, os estudos futuros remetem ao ambiente proposto anteriormente - canais de adução e drenagem e bacia de sedimentação, com vislumbro ao aumento no volume de algas marinhas secas.

\section{REFERÊNCIAS}

1. BALLOU, Ronald H. Gerenciamento da Cadeia de Suprimentos. 5. ed. Porto Alegre: Bookman, 2006. $616 \mathrm{p}$.

2. CHIAVENATO, Idalberto. Iniciação ao planejamento e controle de produção. São Paulo: Mcgraw-hill, 1990.

3. DUNNING, J. H. Toward an eclectic theory of international production: some empirical tests. Journal of International Business Studies, n. 11, spring- summer, p. 9-31, 1980.

4. GIL, A. C. Como elaborar projetos de pesquisa. 5. Ed. São Paulo: Atlas, 2010.

5. JOHANSON, J. and VAHLNE, J. E. The Internationalization Process of the Firm - A Model of Knowledge Development and Increasing Foreign Market Commitments. Journal of International Business Studies. Vol. 8, n.1, 1977, pp 23-32.

6. KOVACS, E. P., MORAES, Walter A. F., OLIVEIRA, Brigitte R. Redefinindo conceitos: um ensaio teórico sobre os conceitos chave das teorias de internacionalização. REGE. Revista de Gestão USP, v. 14, p. 17-29, 2007.

7. MARSHALL, A. Princípios de economia: tratado introdutório. São Paulo: Abril Cultural, 1982. v. 1-2.

8. MINTZBERG, Henry; AHLSTRAND, Bruce; LAMPEL, Joseph. Safári de Estratégia: Um roteiro pela selva do planejamento estratégico. Porto Alegre: Bookman, 2000. 299 p.

9. NEUMANN, Clóvis. Gestão de sistema de produção e operações: Produtividade, Lucratividade e Competitividade. Rio de Janeiro: Elsevier, 2013. 248 p.

10. PORTER, Michael E. A vantagem competitiva das nações. 12. ed. Rio de Janeiro: Elsevier, 1989. $897 \mathrm{p}$.

11. PORTER, M.E. Vantagem competitiva: criando e sustentando um desempenho superior. Rio de Janeiro: Elsevier, 1989. 512 p.

12. SOUZA JUNIOR, Jair Fábio de; CARIO, Silvio Antônio Ferraz; FERNANDES, Ricardo Lopes. Avaliação da participação das micro e pequenas empresas (MPEs) do segmento de confecções de Santa Catarina no mercado externo: caracterização, vantagens e dificuldades de inserção. A Economia em Revista, Campinas, v. 19, n. 2, p.81-99, dez. 2011.

13. TEIXEIRA, V. L.. Marine Natural Products from Seaweeds. Revista Virtual de Química, [s.l.], v. 5, n. 3, p.343-362, 2013. GN1 Genesis Network. DOI: 10.5935/19846835.20130033.

14. YIN, Robert K. Estudo de caso: planejamento e métodos. 2a ed. - Porto Alegre: Bookman, 2001. 